\title{
Identification of Decisive Factors Determining the Continued Use of Rainwater Harvesting Systems for Agriculture Irrigation in Beijing
}

\author{
Xiao Liang ${ }^{1, *}$ and Meine Pieter van Dijk ${ }^{2}$ \\ Received: 14 October 2015; Accepted: 16 December 2015; Published: 25 December 2015 \\ Academic Editor: Ataur Rahman \\ 1 School of Economics, Shenzhen University, Guangdong 518060, China \\ 2 International Institute of Social Studies, The Hague 2518AX, The Netherlands; mpvandijk@iss.nl \\ * Correspondance: x.liang@yahoo.com or liangx@szu.edu.cn; Tel.: +86-755-2673-3256; Fax: +86-755-2653-5344
}

\begin{abstract}
The success or failure of operating a rainwater harvesting system (RWH) depends on both technological and non-technological factors. The importance of non-technological factors in attaining sustainable RWH operation is rarely emphasized. This study aims to assess the contribution of non-technological factors through determining decisive factors involved in the use of RWHs for agriculture irrigation in Beijing. The RWHs for agriculture irrigation in Beijing are not operating as well as expected. If the decisive factors are identified to be non-technological, the significance of non-technological factors will be highlighted. Firstly, 10 impact factors comprising non-technological and technological factors are selected according to both a literature review and interviews with RWH managers. Following this, through an artificial data mining method, rough set analysis, the decisive factors are identified. Results show that two non-technological factors, "doubts about rainwater quality" and "the availability of groundwater" determine whether these systems will continue or cease RWH operation in Beijing. It is, thus, considered necessary to improve public confidence in and motivation on using rainwater for agriculture irrigation, as this is the main obstacle in the sustainable and successful operation of RWHs. Through a case study of RWHs in Beijing, the study verifies the importance of acknowledging non-technological factors to achieve sustainable water management and considers that such factors should receive more attention by decision makers and researchers.
\end{abstract}

Keywords: rainwater harvesting; sustainable water management; decisive factors; rough set analysis

\section{Introduction}

Factors considered to be important in achieving sustainable water management vary amongst the disciplines of engineering, economics, and social sciences. From the respective of technical improvements, the impact factors on rainwater harvesting systems (RWH) include optimal tank size, technical design, and so on [1-5]. Technical improvements could effectively facilitate the operation of a new system, but they do not determine its successful operation. Whether the operation of a system is a success or failure depends on both technological and non-technological factors. Non-technological factors can become considerable obstacles in the adequate functioning of RWHs. Discussions in literature pertaining to non-technological factors in RWHs management contain economic analysis, public perception, and so on [6-10]. However, although these studies have analyzed and explained how factors influence RWHs in a scientific manner, it is rare to emphasize the importance of non-technological factors in attaining sustainable RWHs operation. It is also considered that in some management settings, non-technological factors are more critical than technological ones. Thus, this study aims to assess the contribution of non-technological factors to the efficient running of RWHs. 
The assessment is implemented through determining decisive factors involved in the use of RWHs in a rural area of Beijing. There is scarcity of water in Beijing because of the large population, continual drought, and depletion of groundwater stocks, and water used for agricultural irrigation accounts for around $60 \%$ of the total water use in Beijing. To ameliorate problems associated with this lack of available water, hundreds of RWHs have been constructed for use in agricultural irrigation since the year 2006, which were largely promoted and subsidized by the government. However, most of these systems are actually not operating as well as expected [7] and it is thus very important to determine decisive factors influencing this in Beijing. In the literature, there are studies in discussing determinants of RWHs [11-13], which mostly pursue to find the factors influencing the adoption of RWHs. While, this study emphasizes to prove that non-technological factors are as substantial as technological factors in the successful management of RWHs via the identification of decisive factors.

An artificial data mining method, rough set analysis, was carried out. The sample in this study is small, and the selected impact factors are obtained using partly qualitative and partly quantitative data. Rough set analysis is a mathematical method used to synthesize an approximation of concepts from data that allows information classification [14], even though sample size is small. An extensive theoretical description is provided by Pawlak (1982) and Slowinski $(1991)[15,16]$. The method has rarely been applied to water resource studies [14,17], although it has been applied in other scientific fields such as medicine, economics, software engineering, and urban studies [18-21].

Firstly, non-technological and technological factors were selected according to both a literature review and interviews with RWH managers. Following this, through the method of rough set analysis, impact factors that were decisive in determining the operational success or failure of RWH were identified. If these factors were found to be non-technological, their importance in successful operations were highlighted.

\section{Methodology}

\subsection{Data}

An extensive field study was conducted in a collaborative project between the Chinese Academy of Sciences and the Beijing Agro-Technical Extension Center (BATEC), which focused on RWH practices in the rural areas of Beijing. Some plants are supervised and subsidized by BATEC, which is a professional institute involved with agricultural technology, but others are supervised by other institutes, such as the Beijing Water Saving Office. There is limited access to the plants supervised by the other institutions, and thus the fieldwork was focused only on RWHs supervised by BATEC. The selection criteria determined that each plant used in the study had to have been constructed at least 2 years prior to the study, and that sufficient data on the plant was available. Therefore, only $10 \mathrm{RWHs}$ were selected for study. Although the sample is small, complete data are available for each plant. Locations of the 10 plants are shown in Figure 1, which are distributed within six of Beijing's districts.

The collected rainwater in these RWHs is generally reused for greenhouse irrigation. Figure 2 shows the structure of a typical RWH system. Rainwater goes through the plastic film which is covering the greenhouse down to the ditch in front of the greenhouse, and then moves to the sediment tank for filtering through a big underground pipe. After the solids are deposited, cleaned water enters into the storage tank. When irrigation is required, water is pumped from the storage tank to the greenhouse. 


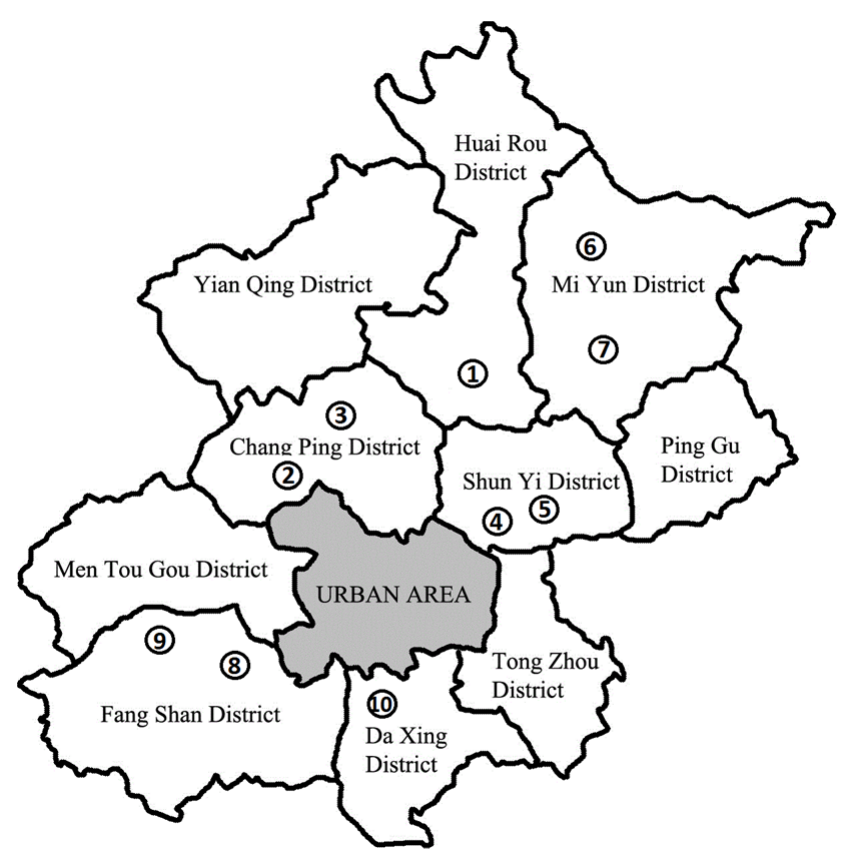

Figure 1. Locations of RWHs studied within Beijing.

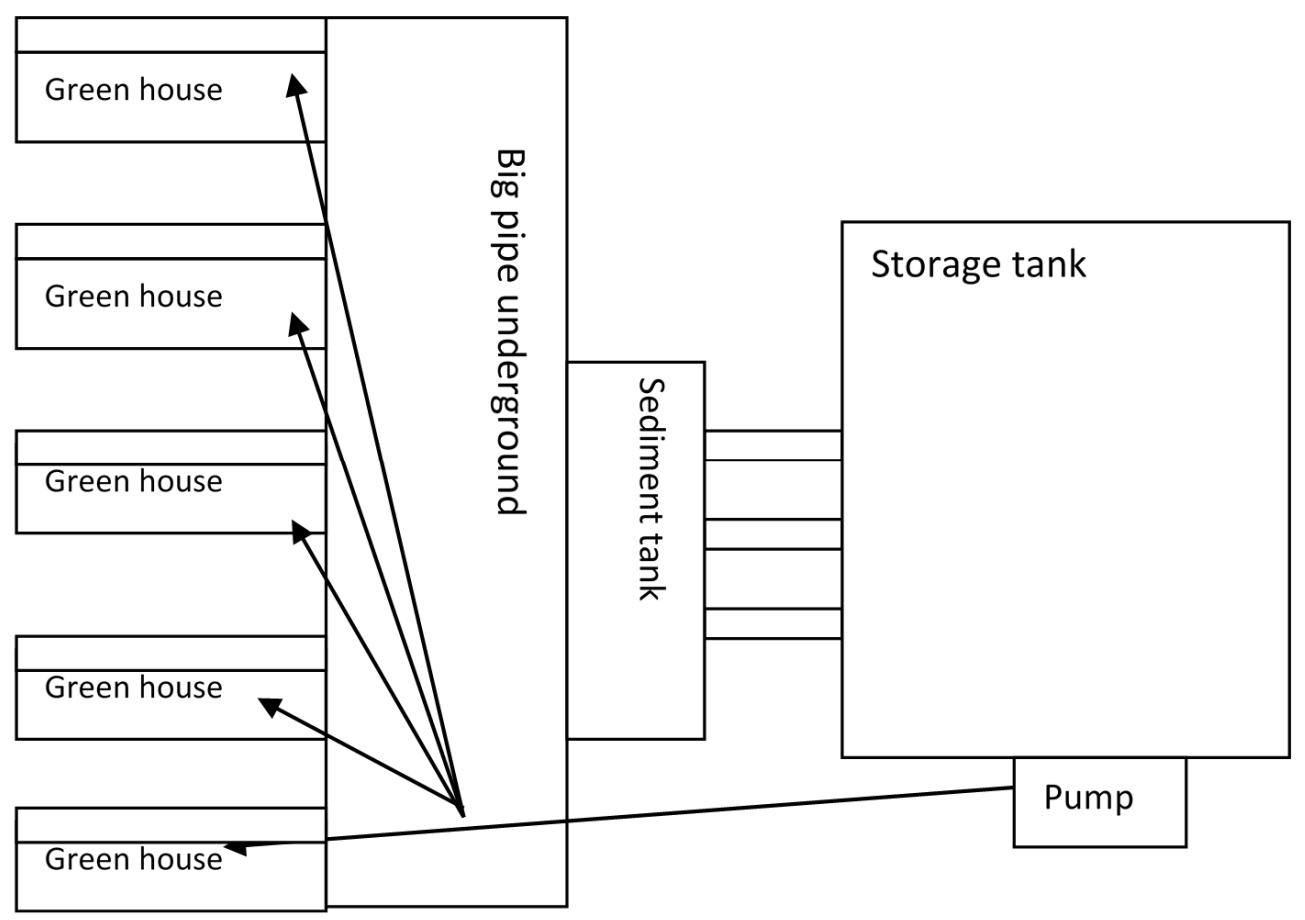

Figure 2. A RWH system [7].

\subsection{Ten Factors}

Based on information obtained from literature and in interviews with managers, the following 10 potential factors were chosen in relation to exerting an impact on the continued operation: (1) subsidies for initial investment; (2) subsidies for operation and maintenance; (3) farmer perception of RWHs; (4) doubts regarding rainwater quality; (5) availability of groundwater; (6) ownership; (7) location; (8) size of storage tank; (9) irrigation methods; and (10) technical problems. Of these 10 factors, factors (1)-(7) are non-technological and (8)-(10) are technological, which are presented in detail below. These 
impact factors are the most crucial to RWHs for agriculture irrigation in Beijing although they may not be the most representative ones.

\section{(1) Subsidies for Initial Investment}

Subsidies for initial investment can effectively assist in reducing the expenditure of farmers [8]. For example, the initial investment for a small plant with a capacity of $50 \mathrm{~m}^{3}$ is approximately $27,000 \mathrm{RMB}$ (approximately 4278 USD) including construction expenses. Small plants are generally constructed on farms with an area of $700 \mathrm{~m}^{2}$. The total annual income of a small family farm in Beijing is, on average, approximately 10,000 RMB (approximately 1574 USD); thus, the initial investment is almost three times the annual income of the owners. When no subsidies are available, farmers have difficulty affording the large initial investment. Therefore, most RWHs in Beijing are provided with subsidies that cover approximately $50 \%$ to $100 \%$ of the initial investment, although some systems receive subsidies covering less than $50 \%$.

\section{(2) Subsidies for Operation and Maintenance}

Several studies have been conducted on recovery of the operational and maintenance costs of RWH [22-24]. The systems need to have a sound maintenance system to enable sustainability and thus insufficient investment in maintenance obstructs the operation of these systems. Subsidies provided for operation and maintenance therefore assist with cost recovery, and may allow continuation of the plant's successful operation. In this study, RWHs managed privately did not receive subsidies for their operation and maintenance, whereas systems managed by state-owned farms or institutes can more readily obtain government subsidies.

\section{(3) Farmer Perception of RWHs}

To ensure the success of RWHs, it is important that farmers have a positive perception of the system $[8,25]$. Local farmers in the Beijing area obtain irrigation water by pumping groundwater. The use of rainwater is typically considered to be more complex than the use of groundwater, despite the fact that technology involved in RWHs is relatively simple. Some farmers in Beijing have a positive perception because rainwater supplements the irrigation water supply, but others consider it unnecessary for unscientific reasons, such the inconvenience of using different methods simultaneously.

\section{(4) Doubts Regarding Rainwater Quality}

Beijing is an industrialized megacity with 13 million residents and a large number of factories. The atmosphere is therefore contaminated by particles, heavy metals, and organic air pollutants [26]. Some users are skeptical about the quality of harvested rainwater due to contamination by air pollution [25] and are concerned that possible pollutants from the atmosphere enter the water and cause an absence of minerals therein. In addition, there is a lack of systematic information for publication whether rainwater in Beijing is suitable or not, although some experiments have been conducted. Such doubts concerning the rainwater quality result in a certain amount of resistance to using rainwater for irrigation.

\section{(5) Availability of Groundwater}

The availability of groundwater is regarded as a potential impact factor in this study, although it is often not discussed in the literature. At present, no clear policies exist relating to the charge for groundwater in Beijing. Therefore, the motivation of famers to use rainwater depends on the availability of groundwater and the cost of accessing it, which is determined by whether the location is mountainous or flat. The availability of groundwater varies according to the position of the plants studied in this paper. For example, two plants are both located in the Mi Yun district (plant 6 and 7, 
as shown in Figure 1) and the groundwater at plant 7 is sufficient, while groundwater at plant 6 is extremely limited.

Groundwater only emerges in certain wells in summer and the wells are dry in other seasons and thus these places are labeled as areas of water scarcity. In other areas it is easy to access groundwater through pumps, and thus resources are sufficient and the locations are considered to be areas with water sufficiency. Farmers in areas where water is scarce have a greater incentive to use alternative water resources than farmers in areas of water sufficiency.

\section{(6) Ownership}

Responsibility of the daily management and operation of a RWHs is determined by its ownership [22]. Some of the plants studied in this paper were managed privately and others were managed by state-owned institutes. Thus the incentives involved in managing and operating the systems were different. In general, the incentives for private-plant managers to operate RWHs are reduced irrigation costs or an increased income. However, the incentive for state-owned-plant managers is not dependent on additional costs or income, and therefore these plants are more likely to be continually operated even when they are not cost-effective.

\section{(7) Location}

Although location is rarely discussed in literature, in this study, it is considered highly relevant as it determines the depth of groundwater and the cost of operating a RWHs. The cost of obtaining groundwater can affect a farmer's incentive to use rainwater [27]. Seven out of the 10 plants studied were located in the northern area of Beijing, which is mostly mountainous, and three were located in the southern area, which is relatively flat and dry. Accordingly, the groundwater level in the north is lower than that in the south. Table 1 shows the depth of groundwater at the northern and southern plants. Farmers living in the northern area need to pump groundwater from deeper wells than farmers in the south. Consequently, higher costs are incurred when pumping water in the northern area, and thereby increasing farmers' motivation to take rainwater.

Table 1. Depth of groundwater at northern and southern plants (2007-2008).

\begin{tabular}{ccccccccccc}
\hline Ground Water & $\mathbf{P}_{\mathbf{1}}$ & $\mathbf{P}_{\mathbf{2}}$ & $\mathbf{P}_{\mathbf{3}}$ & $\mathbf{P}_{\mathbf{4}}$ & $\mathbf{P}_{\mathbf{5}}$ & $\mathbf{P}_{\mathbf{6}}$ & $\mathbf{P}_{\mathbf{7}}$ & $\mathbf{P}_{\mathbf{8}}$ & $\mathbf{P}_{\mathbf{9}}$ & $\mathbf{P}_{\mathbf{1 0}}$ \\
\hline Depth & 28 & 28 & 28 & 32 & 32 & 30 & 30 & 13 & 13 & 20 \\
\hline
\end{tabular}

Notes: Plants $\mathrm{P}_{1}-\mathrm{P}_{7}$ are located in the north and plants $\mathrm{P}_{8}-\mathrm{P}_{10}$ in the south. Data source: Beijing water bulletin (2007-2008).

\section{(8) Size of Storage Tank}

The size of the storage tank is discussed in relation to the successful operation of RWHs [3,28]. The optimal storage size is dependent on precipitation, collection area, water consumption, water saving, and economic issues [28]. In addition, the size of the storage tank can determine the initial investment and operation and maintenance costs involved. For instance, although the operation and maintenance costs of a larger system are lower per unit than the costs of a small system, the total initial investment and operation and maintenance costs of a larger system are higher. In this study, the storage tanks were classified into three categories: small (50-100 $\left.\mathrm{m}^{3}\right)$, medium $\left(450-800 \mathrm{~m}^{3}\right)$, and large $\left(1300-2000 \mathrm{~m}^{3}\right)$.

\section{(9) Irrigation Methods}

Irrigation methods can affect the operation of RWHs [24]. Such methods normally include flood and drip irrigation, where flood irrigation is the traditional method often used by farmers in Beijing and drip irrigation is currently promoted because it effectively reduces water consumption. However, the initial expenditure for drip irrigation is high and not all farmers can afford it. In addition, plants 
using drip irrigation have problems frequently with mud blockages because the diameter of water pipes used in drip irrigation is small enough for mud and rocks to become trapped. Compared with flood irrigation, drip irrigation requires higher maintenance cost.

\section{(10) Technical Problems}

In literature, technical problems are the most-mentioned factors limiting the use of RWHs [23,29], and these can be divided into problems that are severe and those that are less severe. Severe problems consist of, for example, replacement parts required for the plant, and less severe problems consist of parts that are broken and need repair. For the construction of a plant, technical problems can be divided into small and large problems. Large problems involve the implementation of a design that is unsuitable for successful plant operation; small problems involve parts included in a design that require alteration (for example, a shallow ditch being modified to a deep ditch to improve rainwater collection).

This study combines two types of classification and codifies the various technical problems. As shown in Table 2, a coding of 0 indicates that the facility problems are less severe but that the construction design is inappropriate; 1 indicates that the facility needs repair and that the construction design has a small problem; 2 means that some parts of the facility and the construction design require changing; and 3 means that the technical problems of the plant are extremely severe. The facility and its construction are usually designed and implemented by the same institute, and thus they usually work well together. However, when the construction design is inappropriate the facilities are therefore also inadequate for plant operation and thus it is rare to use a coding of 0 . In addition, as RWHs in Beijing are at an early stage of implementation and use, many types of technical problems occur during their operation. All cases studied here had a history of problems in either the facility or related to the construction design.

Table 2. Classification of technical problems.

\begin{tabular}{ccc}
\hline Problems & Big & Small \\
\hline Less serious problems & 0 & 1 \\
Serious problems & 3 & 2 \\
\hline
\end{tabular}

\subsection{Rough Set Analysis}

The information regarding the selected RWHs is a mixture of qualitative and quantitative data. So, the qualitative information is needed to be transferred to quantitative data for further information classification and data mining. Firstly, data pertaining to the 10 factors were all codified as 1, 2, or 3 to establish a consistent database (Table 3). Secondly, as 10 plants were selected for this study, a data matrix was formed for data pertaining to scores for 10 factors at each plant (Table 4). As shown in Table 4, the coded values of the 10 factors for the 10 plants were different, and each factor is denoted by $A_{i}(i=1,2,3, \ldots 10)$; the status of operation is denoted by $D$.

The last row of Tables 3 and 4 indicates the operation status of each plant. Based on interviews with plants managers, one of three statuses was possible concerning the operation of each plant: stopped, interrupted, or continuous. The status of "stopped" means that the plant was no longer functioning, and was represented by a score of 1 . The status of "interrupted" means that the plant was operational but that it stopped irregularly, and was represented by a score of 2 . The status of "continuous" means that the plant was operating successfully and continuously, and this was represented by a score of 3 . In this way, these scores describe the situations of the 10 constructed RWHs studied in Beijing. 
Table 3. Description and coded values of factors.

\begin{tabular}{|c|c|}
\hline Factors & Description and Coded Value \\
\hline $\mathrm{A}_{1}$ : Ownership & $\begin{array}{c}\text { 1: Private } \\
\text { 2: State owned }\end{array}$ \\
\hline $\mathrm{A}_{2}$ : Farme perception of RWHs & $\begin{array}{l}\text { 1: Negative } \\
\text { 2: Positive }\end{array}$ \\
\hline $\mathrm{A}_{3}$ : Doubts regarding rainwater quality & $\begin{array}{l}\text { 1: Yes } \\
\text { 2: No }\end{array}$ \\
\hline $\mathrm{A}_{4}$ : Location & $\begin{array}{l}\text { 1: North } \\
\text { 2: South }\end{array}$ \\
\hline$A_{5}:$ Availability of groundwater & $\begin{array}{l}\text { 1: Sufficient } \\
\text { 2: Scarce }\end{array}$ \\
\hline $\mathrm{A}_{6}:$ Size of storage tank & $\begin{array}{l}\text { 1: Small } \\
\text { 2: Middle } \\
\text { 3: Large }\end{array}$ \\
\hline $\mathrm{A}_{7}$ : Irrigation methods & $\begin{array}{l}\text { 1: Flood irrigation } \\
\text { 2: Drip irrigation }\end{array}$ \\
\hline $\mathrm{A}_{8}:$ Technical problems & $\begin{array}{l}\text { 1: Less serious and small problems } \\
\text { 2: Serious and small problems } \\
\text { 3: Serious and big problems }\end{array}$ \\
\hline$A_{9}$ : Subsidies for initial investment & $\begin{array}{l}\text { 1: } 51 \%-100 \% \text { of the initial investment } \\
\text { 2: } 0 \%-50 \% \text { of the initial investment }\end{array}$ \\
\hline \multirow{2}{*}{$\mathrm{A}_{10}$ : Subsidies for operation and maintenance } & 1: Yes \\
\hline & 2: No \\
\hline D: Status of each plant & $\begin{array}{l}\text { 1: Stopped } \\
\text { 2: Interrupted } \\
\text { 3: Continuous }\end{array}$ \\
\hline
\end{tabular}

Table 4. Codified data matrix of 10 factors and operational status of 10 plants.

\begin{tabular}{|c|c|c|c|c|c|c|c|c|c|c|}
\hline Factors & $\mathbf{P}_{1}$ & $\mathbf{P}_{2}$ & $\mathbf{P}_{3}$ & $\mathbf{P}_{4}$ & $\mathbf{P}_{5}$ & $\mathbf{P}_{6}$ & $\mathbf{P}_{7}$ & $\mathbf{P}_{8}$ & $\mathbf{P}_{9}$ & $\mathbf{P}_{10}$ \\
\hline $\mathrm{A}_{1}$ : Ownership & 1 & 2 & 1 & 1 & 1 & 1 & 1 & 2 & 1 & 2 \\
\hline $\mathrm{A}_{2}$ : Famer perception of RWHs & 1 & 2 & 2 & 2 & 1 & 2 & 2 & 1 & 1 & 1 \\
\hline $\mathrm{A}_{3}$ : Doubts regarding rainwater quality & 1 & 2 & 2 & 1 & 2 & 2 & 2 & 1 & 1 & 1 \\
\hline $\mathrm{A}_{4}$ : Location & 1 & 1 & 1 & 1 & 1 & 1 & 1 & 2 & 2 & 2 \\
\hline$A_{5}$ : Availability of groundwater & 1 & 1 & 1 & 1 & 1 & 2 & 1 & 1 & 1 & 1 \\
\hline $\mathrm{A}_{6}:$ Size of storage tank & 1 & 3 & 3 & 2 & 2 & 1 & 1 & 2 & 1 & 2 \\
\hline $\mathrm{A}_{7}$ : Irrigation methods & 2 & 2 & 1 & 1 & 2 & 1 & 1 & 2 & 2 & 1 \\
\hline $\mathrm{A}_{8}$ : Technical problems & 2 & 3 & 2 & 2 & 1 & 3 & 2 & 2 & 1 & 1 \\
\hline $\mathrm{A}_{9}$ : Subsidies for initial investment & 1 & 1 & 1 & 1 & 1 & 1 & 1 & 2 & 1 & 2 \\
\hline $\mathrm{A}_{10}$ : Subsidies for operation and maintenance & 2 & 1 & 1 & 2 & 1 & 2 & 2 & 1 & 2 & 2 \\
\hline D: Status of each plant & 1 & 2 & 2 & 1 & 2 & 3 & 2 & 1 & 1 & 1 \\
\hline
\end{tabular}

As the operational status of each plant was assumed to be affected by 10 identified factors, these 10 factors $\left(A_{1}, A_{2}, A_{3} \ldots A_{10}\right)$ were regarded as "condition" attributes, and the statuses of the plants $(D)$ were regarded as "decision" attributes. We aimed to determine the causal links between the condition attributes and decision attributes to identify factors determining the cessation or continued operation of the RWHs.

We assumed that the 10 plants $\left(P_{1}, P_{2}, P_{3} \ldots P_{10}\right)$ belonged to a set $U$, namely

$$
U=\left\{P_{1}, P_{2}, P_{3}, P_{4}, P_{5}, P_{6}, P_{7}, P_{8}, P_{9}, P_{10}\right\}
$$

The plants were scored by each attribute based on the information available (shown in Table 4). For example, for $A_{1}=2$ (ownership is "state-owned"), Plants $P_{2}, P_{8}$, and $P_{10}$ had the same score; in 
other words, Plants $P_{2}, P_{8}$, and $P_{10}$ are all state-owned systems. Hence, the set $U$ was classified into subsets based on the scored value of each attribute, as follows:

$$
\begin{aligned}
& U / A_{1}=\left\{\left\{P_{1}, P_{3}, P_{4}, P_{5}, P_{6}, P_{7}, P_{9}\right\},\left\{P_{2}, P_{8}, P_{10}\right\}\right\} \\
& U / A_{2}=\left\{\left\{P_{1}, P_{5}, P_{8}, P_{9}, P_{10}\right\},\left\{P_{2}, P_{3}, P_{4}, P_{6}, P_{7}\right\}\right\} \\
& U / A_{3}=\left\{\left\{P_{1}, P_{4}, P_{8}, P_{9}, P_{10}\right\},\left\{P_{2}, P_{3}, P_{5}, P_{6}, P_{7}\right\}\right\} \\
& U / A_{4}=\left\{\left\{P_{1}, P_{2}, P_{3}, P_{4}, P_{5}, P_{6}, P_{7}\right\},\left\{P_{8}, P_{9}, P_{10}\right\}\right\} \\
& U / A_{5}=\left\{\left\{P_{1}, P_{2}, P_{3}, P_{4}, P_{5}, P_{7}, P_{8}, P_{9}, P_{10}\right\},\left\{P_{6}\right\}\right\} \\
& U / A_{6}=\left\{\left\{P_{1}, P_{6}, P_{7}, P_{9}\right\},\left\{P_{4}, P_{5}, P_{8}, P_{10}\right\},\left\{P_{2}, P_{3}\right\}\right\} \\
& U / A_{7}=\left\{\left\{P_{3}, P_{4}, P_{6}, P_{7}, P_{10}\right\},\left\{P_{1}, P_{2}, P_{5}, P_{8}, P_{9}\right\}\right\} \\
& U / A_{7}=\left\{\left\{P_{1}, P_{2}, P_{3}, P_{4}, P_{5}, P_{6}, P_{7}\right\},\left\{P_{8}, P_{9}, P_{10}\right\}\right\} \\
& U / A_{8}=\left\{\left\{P_{5}, P_{9}, P_{10}\right\},\left\{P_{1}, P_{3}, P_{4}, P_{7}, P_{8}\right\},\left\{P_{2}, P_{6}\right\}\right\} \\
& U / A_{9}=\left\{\left\{P_{1}, P_{2}, P_{3}, P_{4}, P_{5}, P_{6}, P_{7}, P_{9}\right\},\left\{P_{8}, P_{10}\right\}\right\} \\
& U / A_{10}=\left\{\left\{P_{2}, P_{3}, P_{5}, P_{8}\right\},\left\{P_{1}, P_{4}, P_{6}, P_{7}, P_{9}, P_{10}\right\}\right\}
\end{aligned}
$$

In addition, the set $U$ was classified into a subset in terms of the coded value of the decision attribute, as follows:

$$
U / D=\left\{\left\{P_{1}, P_{4}, P_{8}, P_{9}, P_{10}\right\},\left\{P_{2}, P_{3}, P_{5}, P_{7}\right\},\left\{P_{6}\right\}\right\}
$$

If we assume:

$$
Y_{1}=\left\{P_{1}, P_{4}, P_{8}, P_{9}, P_{10}\right\} ; Y_{2}=\left\{P_{2}, P_{3}, P_{5}, P_{7}\right\} ; Y_{3}=\left\{P_{6}\right\}
$$

then

$$
U / D=\left\{Y_{1}, Y_{2}, Y_{3}\right\}
$$

where the subset $Y_{1}$ represents the group of plants with stopped operation, $Y_{2}$ represents the group of plants with interrupted operation, and $Y_{3}$ represents the group of plants with continuous operation. The sets $U / A_{i}(i=1,2,3 \ldots 10)$ may contain the same subset as set $U / D$. If the subset $Y_{j}(j=1,2,3)$ of the set $U / D$ can be determined in any of the sets $U / A_{i}(i=1,2,3 \ldots 10)$, a link between $D$ and $A_{i}$ can be identified. For example, a set $U / A_{m}(m=1$ or 2 or $3 \ldots$ or 10$)$ containing the subset $Y_{n}(n=1$ or 2 or 3$)$ indicates that the group of plants with an $n$th operational status can be characterized by $A_{m}$. In other words, the attribute $A_{m}$ is the critical factor affecting the decision attribute $D$.

The equation for identifying these types of linkages is as follows:

$$
\left(U / A_{\mathrm{i}}\right) \cap(U / D)=\mathrm{Y}_{\mathrm{j}}(i=1,2,3 \ldots 10, j=1,2,3)
$$

Using the aforementioned equations, this study then determined the following:

The term $j=1 \rightarrow i=3$, meaning that $U / A_{3}$ contains $Y_{1}$; The term $j=2 \rightarrow i=3$ and $i=5$, meaning that $U / A_{3}$ and $U / A_{5}$ contain $Y_{2}$; The term $j=3 \rightarrow i=5$, meaning that $U / A_{5}$ contains $Y_{3}$.

These results indicated that only $A_{3}$ and $A_{5}$ are linked with the decision attribute $D$. Accordingly, the conditional causal links of an "if ..., then ..." type were derived (Table 5), which are known as "rules" in rough set theory, where a rule specifies the relationships between condition and decision attributes. 
Table 5. Rules involved in the operation of RWHs.

\begin{tabular}{ccc}
\hline Rule Number & If & Then \\
\hline 1 & $\mathrm{~A}_{3}=1$ & $\mathrm{D}=1$ \\
2 & $\mathrm{~A}_{3}=2$ and $\mathrm{A}_{5}=1$ & $\mathrm{D}=2$ \\
3 & $\mathrm{~A}_{5}=2$ & $\mathrm{D}=3$ \\
\hline
\end{tabular}

\section{Results and Discussion}

Although a considerable amount of money has been invested into RWHs in Beijing, these systems are not often used. This research identified three rules involved in their operation (Table 5) through rough set analysis. The first rule is that when farmers have doubts about the quality of rainwater, operation of the system is discontinued. The second rule is that although farmers have no doubts about the quality of rainwater, they still do not operate the plant continuously if it is possible to obtain sufficient groundwater. The third rule is that only when there is a shortage of groundwater, RWHs operated continuously and successfully. These results are summarized in Table 6. Rule 1 was supported by five plants $\left(P_{1}, P_{4}, P_{8}, P_{9}\right.$, and $\left.P_{10}\right)$, Rule 2 by four plants $\left(P_{2}, P_{3}, P_{5}\right.$, and $\left.P_{7}\right)$, and Rule 3 by one plant $\left(P_{6}\right)$.

Table 6. Description of rules and plants concerned.

\begin{tabular}{cccc}
\hline Rule & If & Then & Plants \\
\hline 1 & Rainwater quality is doubted & Plant operation ceases & $\mathrm{P}_{1}, \mathrm{P}_{4}, \mathrm{P}_{8}, \mathrm{P}_{9}, \mathrm{P}_{10}$ \\
\hline 2 & $\begin{array}{c}\text { Rainwater quality is not doubted but } \\
\text { groundwater source is sufficient }\end{array}$ & Plant operation interrupted & $\mathrm{P}_{2}, \mathrm{P}_{3}, \mathrm{P}_{5}, \mathrm{P}_{7}$ \\
\hline 3 & Groundwater source is not sufficient & Plant operation continues & $\mathrm{P}_{6}$ \\
\hline
\end{tabular}

This study also reveals that the decisive factors concerning whether or not RWHs are operated ("doubts about the rainwater quality" and "availability of groundwater") are both non-technological factors. In comparison with technological factors ("size of storage tank", "irrigation method", and "technical problems"), the two non-technological factors play a critical role in the decision to continue operation of RWHs. These results verify the importance of non-technological factors in the sustainable management of water resources.

To promote RWH for agricultural irrigation in Beijing, the government currently subsidizes and has introduced suitable technology [30]. These actions may facilitate the introduction of RWH. However, continuous operation of RWH depends on the confidence of users in the water quality and their motivation to use the rainwater. Some residents of Beijing believe that city rainwater contains a number of chemicals related to the severe air pollution so that it is unsuitable for agricultural irrigation. RWHs tend to fail when farmers doubt the quality collected rainwater (Rule 1). It is, thus, necessary to alleviate doubts about the quality of rainwater as a crucial first step in promoting the use of RWH. Farmers would use rainwater when they considered it safe for irrigation. Testing of rainwater quality should be performed, and the results should be revealed and explained to the public.

However, some farmers do not doubt the water quality, and there are no technical or financial problems involved, but as they can easily obtain groundwater, the operation may still not continue (Rule 2). According to our interviews and literature review, barriers to using groundwater in Beijing are extremely low [30,31]. Thus, sufficient groundwater resources and low barriers to obtaining the water reduce the motivation on RWHs. Conversely, a shortage of groundwater resources raises farmers' incentive to search for and use other sources of water for irrigation. When groundwater is scarce, RWH continue to operate successfully and continuously (Rule 3). Hence, increasing barriers to obtaining groundwater in water-sufficient areas is a crucial second step in promoting RWHs. Various measures, such as groundwater charges, prohibiting the pumping of new wells, and limiting the 
quantity of groundwater pumping, may be required [7]. It is interesting to note the importance of subjective perception, as in practice, farmers have little information about the pollution of rain water, but perceived pollution causes them to continue using groundwater.

\section{Conclusions}

The present study aimed to examine the effect of non-technological factors on sustainable RWHs management, through identifying critical drivers of the success or failure of RWHs for agriculture irrigation in Beijing. The method of rough set analysis, was applied to analyze partially qualitative and partially quantitative data collected on the functioning of RWH in the Beijing rural area.

Two factors, namely "doubts about rainwater quality" and "availability of groundwater," were determined as decisive factors for the decision to continue or stop using the RWHs. In other words, as long as farmers have doubts about rainwater quality or they consider that there is sufficient groundwater, the newly constructed RWHs will not continue to be operational in the long term. However, if there is a perceived groundwater shortage, farmers will operate the RWHs continuously. Therefore, to enable the sustainable and successful operation of RWHs in Beijing, it is necessary to determine how to improve confidence and motivation in using rainwater. Removing doubts about rainwater quality is an essential step in the promotion of RWHs in Beijing.

Through a case study of RWHs in Beijing, the present study demonstrated that non-technological factors are critical for sustainable water management. It is considered that non-technological factors should receive more attention from researchers and decision makers, as in this instance, they are significant factors in determining the successful, long term operation of this sustainable water-management system.

Acknowledgments: This research was funded by Natural Science Foundation of SZU (Grant No. 201428). We are grateful to the anonymous reviewers for their insightful comments.

Author Contributions: The article was mainly written by Xiao Liang. Meine Pieter van Dijk provided many valuable comments.

Conflicts of Interest: The authors declare no conflict of interest.

\section{References}

1. Campisano, A.; Modica, C. Regional scale analysis for the design of storage tanks for domestic rainwater harvesting systems. Water Sci. Technol. 2012, 66, 1-8. [CrossRef] [PubMed]

2. Burns, M.J.; Letcher, T.D.; Duncan, H.P.; Hatt, B.E.; Ladson, A.R.; Walsh, C.J. The performance of rainwater tanks for stormwater retention and water supply at the household scale: An empirical study. Hydrol. Processes 2015, 29, 152-160. [CrossRef]

3. Mishra, A.; Adhikary, A.K.; Panda, S.N. Optimal size of auxiliary storage reservoir for rain water harvesting and better crop planning in a minor irrigation project. Water Resour. Manag. 2009, 23, 265-288. [CrossRef]

4. Woltersdorf, L.; Liehr, S.; Döll, P. Rainwater harvesting for small-holder horticulture in namibia: Design of garden variants and assessment of climate change impacts and adaptation. Water (Switzerland) 2015, 7, 1402-1421. [CrossRef]

5. Ghimire, S.R.; Johnston, J.M.; Ingwersen, W.W.; Hawkins, T.R. Life cycle assessment of domestic and agricultural rainwater harvesting systems. Environ. Sci. Technol. 2014, 48, 4069-4077. [CrossRef] [PubMed]

6. Karim, M.R.; Bashar, M.Z.I.; Imteaz, M.A. Reliability and economic analysis of urban rainwater harvesting in a megacity in bangladesh. Resour. Conserv. Recycl. 2015, 104, 61-67. [CrossRef]

7. Liang, X.; van Dijk, M.P. Economic and financial analysis on rainwater harvesting for agricultural irrigation in the rural areas of beijing. Resour. Conserv. Recycl. 2011, 55, 1100-1108. [CrossRef]

8. Zuo, J.; Liu, C.; Zheng, H. Cost-benefit analysis for urban rainwater harvesting in Beijing. Water Int. 2010, 35, 195-209.

9. Domènech, L.; Saurí, D. A comparative appraisal of the use of rainwater harvesting in single and multi-family buildings of the metropolitan area of barcelona (spain): Social experience, drinking water savings and economic costs. J. Clean. Product. 2011, 19, 598-608. [CrossRef] 
10. Matos, C.; Bentes, I.; Santos, C.; Imteaz, M.; Pereira, S. Economic analysis of a rainwater harvesting system in a commercial building. Water Resources Manag. 2015, 29, 3971-3986. [CrossRef]

11. Baiyegunhi, L.J.S. Determinants of rainwater harvesting technology (rwht) adoption for home gardening in msinga, kwazulu-natal, south africa. Water SA 2015, 41, 33-40. [CrossRef]

12. Recha, C.W.; Mukopi, M.N.; Otieno, J.O. Socio-economic determinants of adoption of rainwater harvesting and conservation techniques in semi-arid tharaka sub-county, kenya. Land Degrad. Dev. 2015, 26, 765-773. [CrossRef]

13. He, X.F.; Cao, H.; Li, F.M. Econometric analysis of the determinants of adoption of rainwater harvesting and supplementary irrigation technology (rhsit) in the semiarid loess plateau of china. Agric. Water Manag. 2007, 89, 243-250. [CrossRef]

14. Zhang, Z.; Xu, Z. Rough set method to identify key factors affecting precipitation in lhasa. Stoch. Environ. Res. Risk Assess. 2009, 23, 1181-1186. [CrossRef]

15. Pawlak, Z. Rough sets. Int. J. Comput. Inf. Sci. 1982, 11, 341-356. [CrossRef]

16. Slowinski, R. Intelligent Decison Support: Handbook of Applications and Advances of Rough Set Theory; Kluwer Academic Publishers: Norwell, MA, USA, 1991.

17. Barbagallo, S.; Consoli, S.; Pappalardo, N.; Greco, S.; Zimbone, S.M. Discovering reservior operating rules by a rough set approach. Water Resour. Manag. 2006, 20, 19-36. [CrossRef]

18. Nijkamp, P.; Van der Burch, M.; Vindigni, G. A comparative institutional evaluation of public-private partnerships in dutch urban land-use and revitalisation projects. Urban. Stud. 2002, 39, 1865-1880. [CrossRef]

19. Baycan-Levent, T.; Nijkamp, P. Planning and management of urban green spaces in europe: Comparative analysis. J. Urban. Plan. Dev. 2009, 135, 1-12. [CrossRef]

20. Wu, C.; Yue, Y.; Li, M.; Adjei, O. The rough set theory and applications. Eng. Comput. 2004, $21,488-511$. [CrossRef]

21. Nijkamp, P.; Rietveld, P.; Spierdijk, L. A meta-analytic comparison of determinants of public transport use: Methodology and application. Environ. Plan. B: Plan. Des. 2000, 27, 893-903. [CrossRef]

22. Mushtaq, S.; Dawe, D.; Hafeez, M. Economic evaluation of small multi-purpose ponds in the zhanghe irrigation system, China. Agric. Water Manag. 2007, 91, 61-70. [CrossRef]

23. Oweis, T.; Hachum, A. Water harvesting and supplemental irrigation for improved water productivity of dry farming systems in west asia and north Africa. Agric. Water Manag. 2006, 80, 57-73. [CrossRef]

24. Berthelot, P.B.; Robertson, C.A. A comparative study of the financial and economic viability of drip and overhead irrigation of sugarcane in mauritius. Agric. Water Manag. 1990, 17, 307-315. [CrossRef]

25. Song, J.; Han, M.; Kim, T.; Song, J. Ras a sustainable water supply option in banda aceh. Desalination 2009, 248, 233-240. [CrossRef]

26. Helmreich, B.; Horn, H. Opportunities in rainwater harvesting. Desalination 2009, 248, 118-124. [CrossRef]

27. Liang, X.; van Dijk, M.P. Optimal level of groundwater charge to promote rainwater usage for irrigation in rural beijing. Water 2011, 3, 1077-1091. [CrossRef]

28. Campisano, A.; Modica, C. Optimal sizing of storage tanks for domestic rainwater harvesting in sicily. Resour. Conserv. Recycl. 2012, 63, 9-16. [CrossRef]

29. Hatibu, N.; Mutabazi, K.; Senkondo, E.M.; Msangi, A.S.K. Economics of rainwater harvesting for crop enterprises in semi-arid areas of east africa. Agric. Water Manag. 2006, 80, 74-86. [CrossRef]

30. Wang, Y.; Wang, H. Sustainable use of water resources in agriculture in beijing: Problems and countermeasures. Water Policy 2005, 7, 345-357.

31. Yang, H.; Zhang, X.; Zehnder, A.J.B. Water scarcity, pricing mechanism and institutional reform in northern china irrigated agriculture. Agric. Water Manag. 2003, 61, 143-161. [CrossRef]

(c) 2015 by the authors; licensee MDPI, Basel, Switzerland. This article is an open access article distributed under the terms and conditions of the Creative Commons by Attribution (CC-BY) license (http://creativecommons.org/licenses/by/4.0/). 